\title{
Acinar cell carcinoma of pancreas
}

INSERM

\section{Source}

INSERM. (1999). Orphanet: an online rare disease and orphan drug data base. Acinar cell carcinoma of pancreas. ORPHA:424046

A very rare, malignant, epithelial tumor of the pancreas characterized, macroscopically, by a usually large, well-circumscribed, fully or partially encapsulated, solid mass, often with hemorrhage, necrosis and cystic changes, in any portion of the pancreas and, histologically, by neoplastic cells with variable degrees of differentiation and morphology, rang ing from acinar structures similar to normal pancreatic acini to large sheets of poorly differentiated neoplastic cells. Presenting symptoms are typically non-specific and include abdominal pain, weight loss, vomiting, nausea, and/or, less commonly, jaundice. Immunohistochemical evidence of acinar-specific products is observed. Association with Lynch syndrome, familial adenomatous polyposis, and pancreatic panniculitis has been reported. 